\title{
How Does the Evaluation of the GPM IMERG Rainfall Product Depend on Gauge Density and Rainfall Intensity? 0
}

\author{
FUQIANG TIAN AND SHIYU HOU \\ Department of Hydraulic Engineering, State Key Laboratory of Hydro-science and Engineering, Tsinghua University, Beijing, China \\ LONG YANG \\ Department of Civil and Environmental Engineering, Princeton University, Princeton, New Jersey \\ HONGCHANG HU \\ Department of Hydraulic Engineering, State Key Laboratory of Hydro-science and Engineering, Tsinghua University, Beijing, China
}

\author{
AIZHONG HOU
}

Hydrology Bureau, Ministry of Water Resources, Beijing, China

(Manuscript received 21 August 2017, in final form 4 December 2017)

\begin{abstract}
This study investigates the dependency of the evaluation of the Integrated Multisatellite Retrievals for Global Precipitation Measurement (IMERG) rainfall product on the gauge density of a ground-based rain gauge network as well as rainfall intensity over five subregions in mainland China. High-density rain gauges (1.5 gauges per $100 \mathrm{~km}^{2}$ ) provide exceptional resources for ground validation of satellite rainfall estimates over this region. Eight different gauge networks were derived with contrasting gauge densities ranging from 0.04 to 4 gauges per $100 \mathrm{~km}^{2}$. The evaluation focuses on two warm seasons (April-October) during 2014 and 2015. The results show a strong dependency of the evaluation metrics for the IMERG rainfall product on gauge density and rainfall intensity. A dense rain gauge network tends to provide better evaluation metrics, which implies that previous evaluations of the IMERG rainfall product based on a relatively low-density gauge network might have underestimated its performance. The decreasing trends of probability of detection with gauge density indicate a limited ability to capture light rainfall events in the IMERG rainfall product. However, IMERG tends to overestimate (underestimate) light (heavy) rainfall events, which is a consistent feature that does not show strong dependency on gauge densities. The results provide valuable insights for the improvement of a rainfall retrieval algorithm adopted in the IMERG rainfall product.
\end{abstract}

\section{Introduction}

Satellite-derived rainfall products emerge as promising approaches for obtaining rainfall estimates at regional and global scales (e.g., Tang et al. 2016b; Javanmard et al. 2010; Amitai et al. 2012). The accuracy of satellite rainfall products needs to be evaluated against ground-based rain gauges before further application.

Supplemental information related to this paper is available at the Journals Online website: https://doi.org/10.1175/ JHM-D-17-0161.s1.

Corresponding author: Fuqiang Tian, tianfq@tsinghua.edu.cn
However, there are intrinsic deviations in the evaluation due to the inconsistency of representative spatial scales between satellite rainfall products (gridbox scale) and ground-based rain gauge observations (point scale; e.g., Hu et al. 2014; Kim et al. 2017). Interpolation of point measurements from rain gauges is the only option to obtain spatial precipitation information. The representation of spatial rainfall variability can be noticeably improved by the interpolation of a high-density rain gauge network (e.g., Girons Lopez et al. 2015). The World Meteorological Organization (WMO) requires that the control area of a single rain gauge should be around $600 \mathrm{~km}^{2}$ for temperate plains (approximately 0.17 gauges per $100 \mathrm{~km}^{2}$ ) (WMO 1965). Larger gauge 


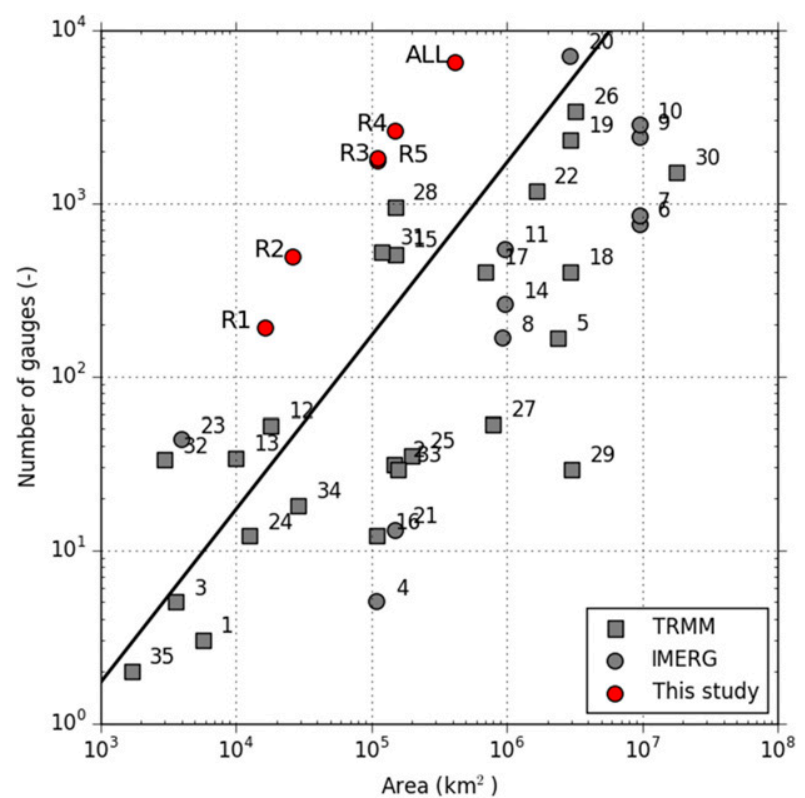

FIG. 1. Overview of the gauge densities adopted in previous studies on the evaluation of satellite rainfall products: squares represent TRMM Multisatellite Precipitation Analysis (TMPA; Huffman et al. 2007) and dots represent the IMERG rainfall product. Red dots highlight the gauge densities of five subregions adopted in this study (also see Fig. 2 for details). The numbers marked beside each symbol correspond to the ID listed in Table A1. The black line highlights the gauge density required by the WMO for temperate plains $\left(0.17\right.$ gauges per $\left.100 \mathrm{~km}^{2}\right)$.

densities are required over regions with strong spatial rainfall variability, for instance, mountainous regions and arid/semiarid regions (e.g., WMO 1965; Goodrich et al. 1995). As noted by United Nations (2006), the inadequate coverage and sustainability of monitoring networks continues to be one of the main issues for poor water management practices. Most previous studies on the evaluation of satellite rainfall products were based on rain gauge networks with gauge densities less than 0.17 gauges per $100 \mathrm{~km}^{2}$ (see Fig. 1 and appendix A for details), which might lead to uncertain results in the evaluation of the existing satellite rainfall products.

The main objective of this study is to investigate the dependency of the performance of satellite rainfall products on the density of the ground-based rain gauge network as well as rainfall intensity. The satellite rainfall product we evaluated in this study is the level-3 Integrated Multisatellite Retrievals for GPM (IMERG) from the Global Precipitation Measurement (GPM) mission (e.g., Hou et al. 2014; Huffman et al. 2015a,b). The IMERG rainfall product, with a $0.1^{\circ}$ spatial resolution and a 30-min temporal resolution, has been extensively evaluated and applied in recent years since its

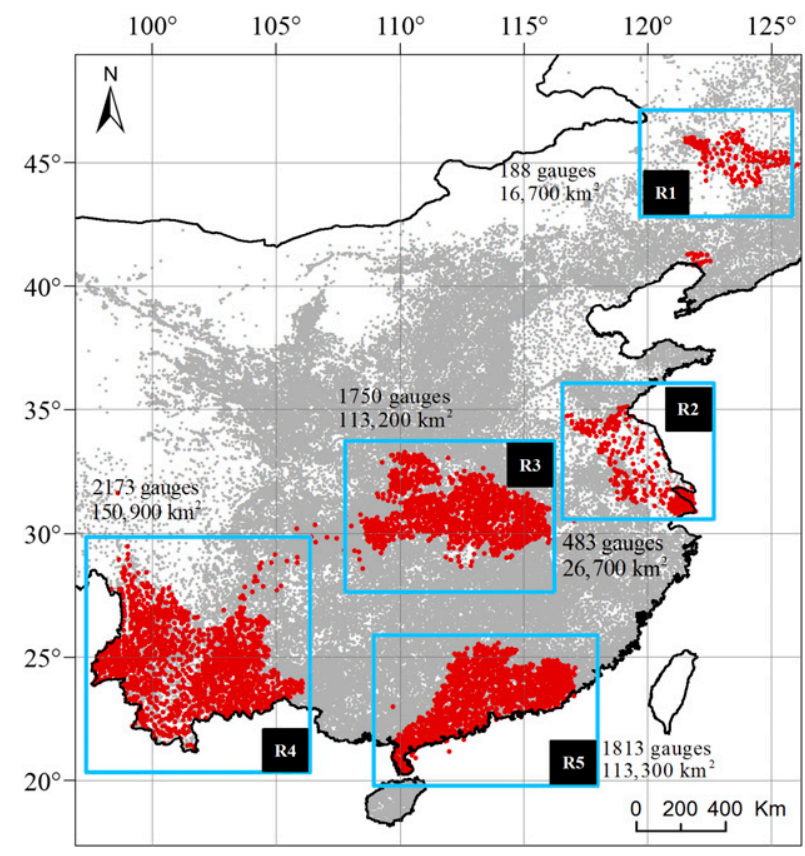

FIG. 2. Spatial distribution of rain gauges over mainland China. Red dots represent the locations of 6407 selected rain gauges used in this study. Gray dots represent the entire set of more than 100000 ground-based rain gauges. Five subregions are outlined by blue boxes. The number of rain gauges and coverage for each subregion are marked in the figure.

release in March 2014 (e.g., Turk and Xian 2013; Liu 2016; Tang et al. 2016a; Sahlu et al. 2016; Xu et al. 2017). As shown in Fig. 1, previous evaluations are extensively based on rain gauge networks with relatively low densities (see appendix A for a selection of representative studies). Previous studies also highlight the strong dependence of the performance of satellite rainfall products on rainfall intensity (e.g., Xu et al. 2017; He et al. 2017). However, the joint dependence of the performance of the IMERG rainfall product on both gauge density and rainfall intensity has not been examined in previous studies and is only possible with a high-density rain gauge network.

\section{Data and methodology}

Our study region is mainland China, which has an exceptionally dense coverage of more than 100000 ground-based rain gauges (Fig. 2). The rain gauge network is maintained by the Hydrology Bureau in the Ministry of Water Resources of China. Unlike the rain gauge datasets used in previous studies (e.g., Gao and Liu 2013; Ning et al. 2016; Shen et al. 2010; Tang et al. 2016a; W. Wang et al. 2017; Guo et al. 2016; Tang et al. 2016b; Chen and Li 2016; Xu et al. 2017; Ma et al. 2016), 
TABLE 1. Methods of creating rain gauge networks with contrasting densities.

\begin{tabular}{lclc}
\hline \hline $\begin{array}{c}\text { Density } \\
\text { (gauges per GPM grid box) }\end{array}$ & No. of gauges & \multicolumn{1}{c}{ Method of selecting GPM grid boxes } & No. of gauge-grid box pairs \\
\hline 0.04 & 1 & Expanding 25 grids centered on the gauge & 4208 \\
0.0625 & 1 & Expanding 16 grids centered on the gauge & 4208 \\
0.11 & 1 & Expanding 9 grids centered on the gauge & 4208 \\
0.25 & 1 & Expanding 4 grids centered on the gauge & 4208 \\
1 & 1 & Selecting the grid that contains the gauge & 4208 \\
2 & 2 & Selecting the grid that contains the two gauges & 1431 \\
3 & 3 & Selecting the grid that contains the three gauges & 505 \\
4 & 4 & Selecting the grid that contains the four gauges & 168 \\
\hline
\end{tabular}

the rain gauge network used in this study serves the main purpose of warning for extreme rainfall and floods. We note that all rain gauges in the network are automatic rain gauges with fine temporal scales (i.e., hourly and subhourly) and high precision of rainfall observations during the warm season (April-October). Our study period is April-October during 2014 and 2015. Strict quality controls have been applied to the ground-based rain gauge observations: 1) gauges without a complete record during April-October during 2014 and 2015 are discarded, even if only a single record is missing, and 2) gauges with "erroneous" records (negative or anomalously large hourly precipitation) are removed from the dataset. The erroneous records might be due to wrong coding, units, or observations of solid precipitation (e.g., snow). Out of the 100000 rain gauges, 6407 gauges passed the quality control procedures, and they span a complete time series of the two warm-season periods (see Fig. 2 for spatial distributions of the rain gauges). The 6407 gauges are clustered over five subregions of mainland China, that is, northeast, Yangtze-Huai River, middle Yangtze River, southwest, and Pearl River (see Fig. 2 for the number of gauges in each subregion). We note that the main conclusions of this study do not present specific dependence on the region. Thus, the following analyses will be presented with all five subregions lumped together.

The selected 6407 gauges are distributed over 4208 GPM grid boxes, with each grid box containing at least one rain gauge. The overall density of the rain gauge network is 1.5 gauges per $100 \mathrm{~km}^{2}$, approximately 10 times higher than the required density by WMO. The percentage of grid boxes with more than two, three, and four gauges per $100 \mathrm{~km}^{2}$ are $34 \%, 12 \%$, and $4 \%$, respectively. According to the authors' best knowledge, this is the densest rain gauge network used in evaluating the performance of existing satellite rainfall products by far. The dense rain gauge network provides exceptional resources for the evaluation of the IMERG rainfall product over this region.
We further derived eight different gauge networks with contrasting gauge densities from the original rain gauge network. For gauge densities smaller than 1 gauge per $100 \mathrm{~km}^{2}$, for instance, 1 gauge per $400 \mathrm{~km}^{2}$, we selected four neighboring grid boxes centered over the rain gauge and derived the mean values of rainfall over the four grid boxes from the IMERG rainfall product. For gauge densities larger than 1 gauge per $100 \mathrm{~km}^{2}$, for instance, 2 gauges per $100 \mathrm{~km}^{2}$, the mean value of the two gauges' rainfall is paired with that from the grid box. The number of grid box-gauge pairs as well as the selection methods for each network is listed in Table 1.

Four error metrics describe the deviation of rainfall magnitudes for the IMERG rainfall product from the rain gauge observations, that is, Bias, Abias, mean error (ME), and mean absolute error (MAE), and are computed as follows:

$$
\begin{aligned}
\text { Bias }= & \frac{\sum_{i=1}^{n} \mathrm{GPM}_{i}-\sum_{i=1}^{n} \mathrm{GAU}_{i}}{\sum_{i=1}^{n} \mathrm{GAU}_{i}}, \\
\text { Abias }= & \frac{\sum_{i=1}^{n}\left|\mathrm{GPM}_{i}-\mathrm{GAU}_{i}\right|}{\sum_{i=1}^{n} \mathrm{GAU}_{i}}, \\
\mathrm{ME} & =\frac{\sum_{i=1}^{n} \mathrm{GPM}_{i}-\sum_{i=1}^{n} \mathrm{GAU}_{i}}{n}, \text { and } \\
\mathrm{MAE} & =\frac{\sum_{i=1}^{n}\left|\mathrm{GPM}_{i}-\mathrm{GAU}_{i}\right|}{n},
\end{aligned}
$$

where $n$ is the total number of GPM grid box-gauge data pairs, $i$ is the $i$ th value of the GPM product data and gauge observation, GAU represents the gauge observations, and $\overline{\mathrm{GAU}}$ is the average of the gauge observations. GPM and $\overline{\text { GPM }}$ represent the GPM rainfall estimates and their average, respectively. 
The IMERG rainfall product's skill to detect the occurrence of rainfall events with rainfall intensity exceeding specific thresholds is evaluated using the probability of detection (POD) and frequency of hit (FOH; see http://www.cawcr.gov.au/projects/verification/ for a comprehensive list of the evaluation metrics), which are defined as

$$
\begin{aligned}
& \mathrm{POD}=\frac{n_{11}}{n_{11}+n_{01}} \text { and } \\
& \mathrm{FOH}=\frac{n_{11}}{n_{11}+n_{10}},
\end{aligned}
$$

where $n_{11}$ represents a hit (i.e., the event was detected to occur by satellite and observed to occur also), $n_{10}$ represents a false alarm (i.e., the event was detected to occur but not observed to occur), and $n_{01}$ represents a miss (i.e., the event was not detected to occur but observed to occur).

We applied different thresholds in the definition of a rainfall event, highlighting the performance of the IMERG rainfall product for rainfall events with different intensities, as will be elaborated on in section 3 . The evaluation is implemented at both hourly and daily scales. The IMERG rainfall product is integrated into hourly and daily scales from the original datasets with a temporal resolution of $30 \mathrm{~min}$. Observations from rain gauges are also integrated into hourly and daily scales to match IMERG. Daily records are obtained by integrating hourly records from 0000 UTC (0800 LST) to 0000 UTC (0800 LST) of the next day for both IMERG and rain gauges.

\section{Results}

Figure 3 shows the evaluation results of the four error metrics (i.e., Bias, Abias, ME, and MAE) over eight different gauge density networks. We further classified the grid box-gauge pairs over different networks according to the observed rainfall intensities. Light and moderate rainfall uses the thresholds of $5 \mathrm{~mm} \mathrm{day}^{-1}$ at the daily scale and $1 \mathrm{~mm} \mathrm{~h}^{-1}$ at the hourly scale, that is, rainfall smaller (larger) than threshold is defined as light (moderate) rainfall. The metrics tend to be improved with the increased gauge densities (see the black lines and black dots in Fig. 3), indicating that the performance of the IMERG rainfall product is underestimated with rain gauge networks of lower densities. Another notable feature from Fig. 3 is that there are strong dependencies of the four bias metrics on both rainfall intensities and gauge densities. The four bias metrics are overall controlled by the biases of moderate rainfall intensities for both the absolute values and trends. Changes of bias metrics for the category of light rainfall intensities $\left(0-5 \mathrm{~mm} \mathrm{day}^{-1}\right.$ and $\left.0-1 \mathrm{~mm} \mathrm{~h}^{-1}\right)$ present strong deviations from that of moderate rainfall intensities $\left(>5 \mathrm{~mm} \mathrm{day}^{-1}\right.$ and $\left.>1 \mathrm{~mm} \mathrm{~h}^{-1}\right)$. There are significant decreasing trends (i.e., slopes of the trend lines are significantly different from zero; see Table $\mathrm{S} 1$ in the online supplement for details of the significance test results) of both Bias and Abias values with the increased gauge densities (Figs. 3a-d). With the increased gauge densities, the performance of the IMERG rainfall product in estimating values of light rainfall $\left(0-5 \mathrm{~mm} \mathrm{day}^{-1}\right.$ and $0-1 \mathrm{~mm} \mathrm{~h}^{-1}$ ) has been significantly improved. Different slope values also exist between heavy rainfall and light rainfall because of the meteorological patterns in southern and eastern China. Mesoscale convective systems play a dominant role in shaping the heavy rainfall climatology over mainland China (southern and eastern China, more specifically) during late spring and summer (April-October). These convective systems typically can survive from hours to days and can cover a spatial scale of around $200-2000 \mathrm{~km}^{2}$ (Ding and Zhang 2009). Gauge density should not be the key factor in accurately estimating the grid-average rain rate (at a scale of around $100 \mathrm{~km}^{2}$ ). We would expect different results for arid/semiarid regions (such as northwestern China) where heavy rainfall events are frequently related to localized, short-lived convective storm cells. We also note that GPM underestimates moderate rainfall $\left(>5 \mathrm{~mm} \mathrm{day}^{-1}\right.$ and $>1 \mathrm{~mm} \mathrm{~h}^{-1}$ ) but overestimates light rainfall $\left(0-5 \mathrm{~mm} \mathrm{day}^{-1}\right.$ and $0-1 \mathrm{~mm} \mathrm{~h}^{-1}$; see the Bias and ME values in Fig. 3), which is a consistent feature across all networks and does not depend on gauge densities. We note that the consistencies (as represented by the correlation coefficient) between rain gauges and the IMERG rainfall product increase with gauge densities (with a significance level of $1 \%$; results not shown).

We evaluate the performance of the IMERG rainfall product in detecting rainfall occurrence with two metrics based on the contingency description statistics, that is, POD and FOH (Fig. 4). The definitions of a rainfall event, a moderate rainfall event, and a heavy rainfall event are based on the thresholds of $0 \mathrm{~mm} \mathrm{day}^{-1}$ $\left(0 \mathrm{~mm} \mathrm{~h}^{-1}\right), 5 \mathrm{~mm} \mathrm{day}^{-1}\left(1 \mathrm{~mm} \mathrm{~h}^{-1}\right)$, and $10 \mathrm{~mm} \mathrm{day}^{-1}$ $\left(5 \mathrm{~mm} \mathrm{~h}^{-1}\right)$, respectively. The performance of the IMERG rainfall product for the daily rainfall estimates is overall superior to hourly rainfall estimates (also see Tan et al. 2017), with higher values of POD and FOH (as shown in Fig. 4). This is a consistent feature regardless of gauge densities and rainfall intensities. The dependencies of the two evaluation metrics on gauge densities and rainfall intensities are still pronounced. There is a decreasing trend of POD with gauge densities (with a significance level of $1 \%$ ), while $\mathrm{FOH}$ presents 

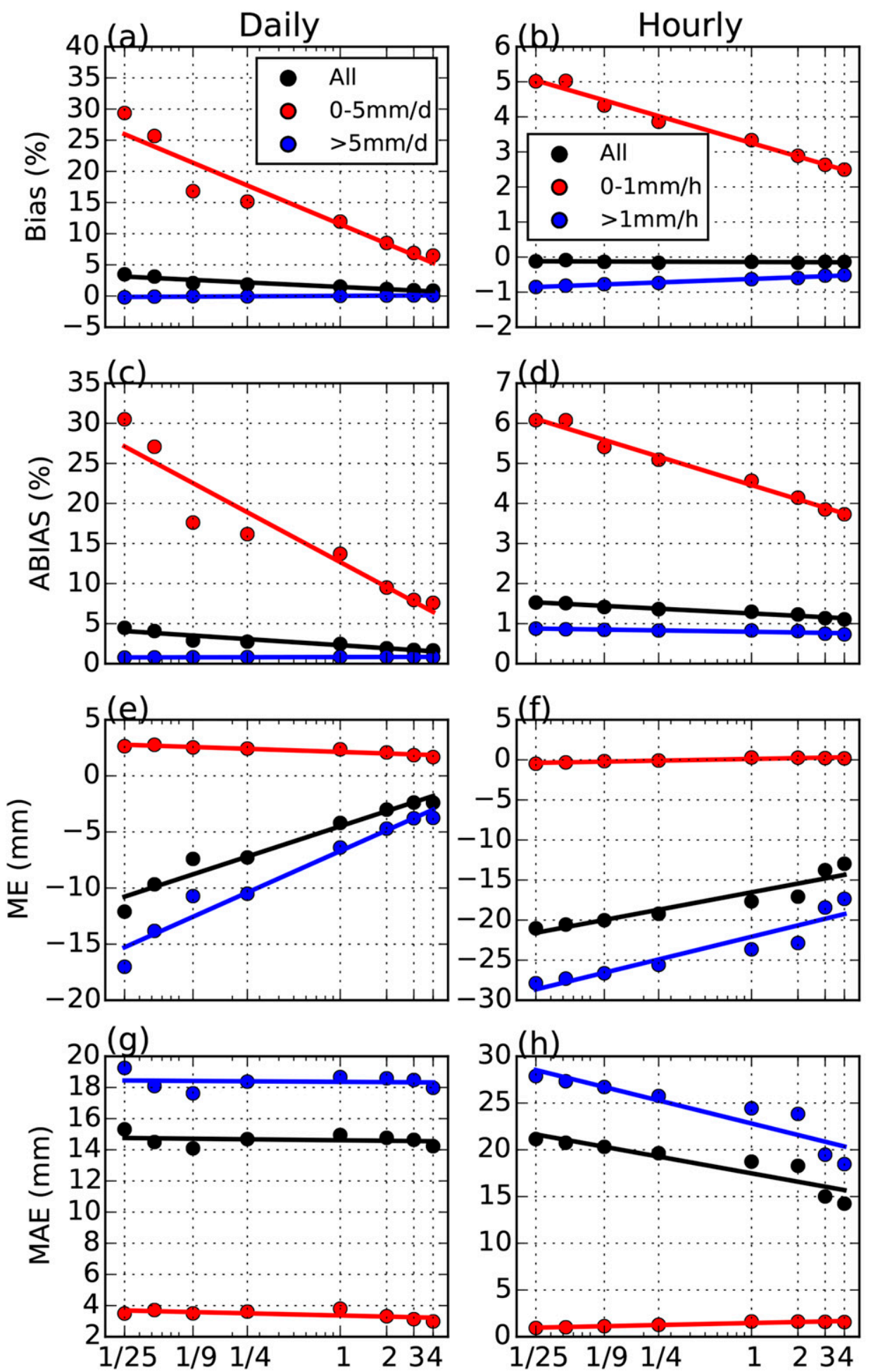

Density (\# gauges/100 $/ \mathrm{km}^{2}$ )

FIG. 3. Evaluation metrics differentiated by gauge densities and rainfall intensities for the (left) daily scale and (right) hourly scale: (a),(b) Bias; (c),(d) Abias; (e),(f) ME; and (g),(h) MAE. 

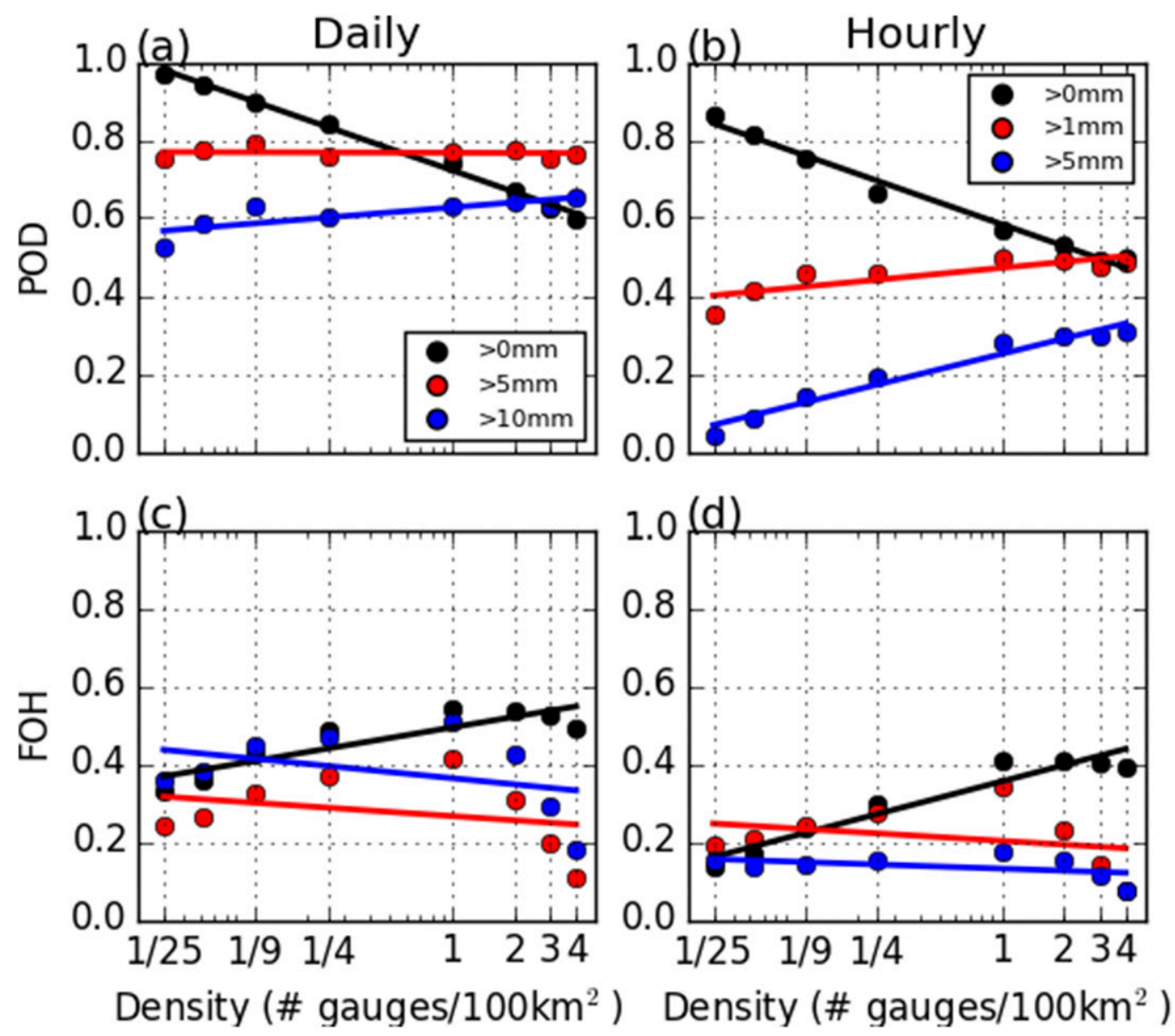

FIG. 4. Evaluation metrics differentiated by gauge densities and rainfall intensities for the (left) daily scale and (right) hourly scale: (a),(b) POD and (c),(d) FOH.

increasing trends with gauge densities. However, the trends of POD and FOH for moderate and heavy rainfall events are distinct from those of light rainfall occurrences; for instance, POD for heavy rainfall events (with rainfall intensity exceeding $10 \mathrm{~mm} \mathrm{day}^{-1}$ and $5 \mathrm{~mm} \mathrm{~h}^{-1}$ ) increases with gauge density (with a significance level of $1 \%$ ), indicating that the performance of the IMERG rainfall product in detecting heavy rainfall events is better when evaluated from a dense rain gauge network, while FOH exhibits a slightly weak increasing trend before 1 gauge per $100 \mathrm{~km}^{2}$, and then sharply decreases after. The overall trend of FOH only shows a weak decreasing trend, indicating more false alarms of heavy rainfall events with a high-gauge-density network.

The contrasting trends of POD and FOH for rainfall occurrence $\left(>0 \mathrm{~mm} \mathrm{day}^{-1}\right.$ and $\left.0 \mathrm{~mm} \mathrm{~h}^{-1}\right)$ can be attributed to the contrasting changes of missing rates $n_{01}$ and false alarms $n_{10}$. With the increased gauge densities, there tend to be more rainfall events missed by GPM but observed by gauges (increased $n_{01}$ ), while fewer rainfall events are reported by GPM but not observed by gauges (reduced $n_{10}$ ). The results can be explained by a basic intuition that we would expect a higher probability of detection in light rainfall events with more rain gauges distributed in a specific region (e.g., a single GPM grid box; see appendix B for schematic explanation). Since the measured fraction of rainfall events from the rain gauge network is more accurate with a higher gauge density, the decreasing values of POD can be related to the increased number of light rainfall events observed by the gauge network but missing from the IMERG rainfall product. As light rainfall corresponds to small POD values (Fig. 5), when more light rainfall events are included, there is no doubt that POD decreases. This is consistent with the increasing trend of POD for heavy rainfall events at both daily and hourly scales (Figs. 4a,b).

To further verify our hypothesis, we evaluate the changes of POD for different rainfall categories (Fig. 5). The IMERG rainfall product tends to provide a better performance in detecting rainfall events with relatively 

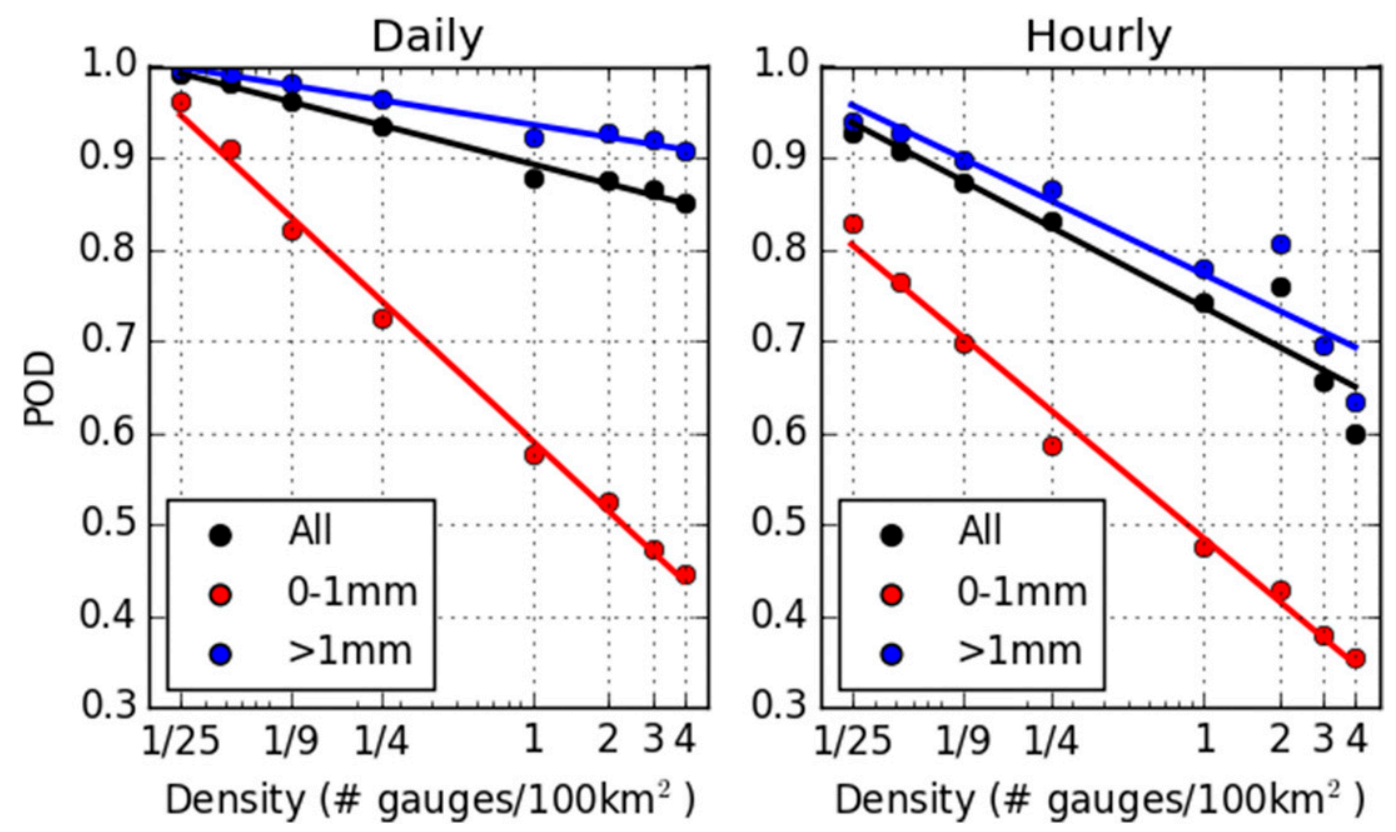

FIG. 5. Values of POD for different gauge densities and rainfall intensities.

large rainfall intensities $\left(>1 \mathrm{~mm} \mathrm{day}^{-1}\right.$ and $\left.>1 \mathrm{~mm} \mathrm{~h}^{-1}\right)$, while the performance deteriorates drastically in detecting light rainfall events $\left(0-1 \mathrm{~mm}\right.$ day $^{-1}$ and $\left.0-1 \mathrm{~mm} \mathrm{~h}^{-1}\right)$. This is a consistent feature across eight rain gauge networks. Even though the bias metrics for light rainfall events are improved with gauge density (Fig. 3), we note that the occurrence of light rainfall events is still poorly represented in the IMERG rainfall product. With an increased number of light rainfall events observed in rain gauges, the values of POD present decreasing trends, which indicates the missing representation of light rainfall events in the IMERG rainfall product. The large missing rates of light rainfall by IMERG can also be related to the minimum detectable rain rate, which is an intrinsic nature of the precipitation sensor and needs to be upgraded in the future (see Hou et al. 2014 for details).

\section{Concluding remarks}

In this study, we investigated the dependency of the evaluation of the IMERG rainfall product on the gauge density of a ground-based rain gauge network as well as rainfall intensity. Our study is based on a dense rain gauge network (1.5 gauges per $100 \mathrm{~km}^{2}$ on average) over five subregions in mainland China. For the first time, we identified the strong dependency of the evaluation metrics for the IMERG rainfall product on gauge density and rainfall intensity. We found that a dense rain gauge network provides better evaluation metrics of the IMERG rainfall product, with the exception of POD.
Previous studies based on relatively lower-density gauge networks might thus have underestimated the performance of the IMERG rainfall product. The decreased values of POD over denser rain gauge networks can be attributed to the increased missing representations of light rainfall events in the IMERG rainfall product. Our results highlight the necessity of differentiating rainfall events according to their intensities while evaluating the performance of satellite rainfall products. The strong dependency of the IMERG rainfall product on rainfall intensity has also been identified in previous studies (e.g., Xu et al. 2017; He et al. 2017). We also note that the IMERG rainfall product tends to provide an underestimation of heavy rainfall but overestimation of light rainfall [see, e.g., Xu et al. (2017) and He et al. (2017) for details], which is a consistent feature independent of gauge densities. The dependence of the performance of the satellite rainfall product on rainfall intensity might be related to measuring techniques implemented or rainfall retrieval algorithms and needs to be examined in the future. One limitation of this study is that it is based on a relatively short temporal record (i.e., two warm seasons). However, we believe timely assessment on the newly released satellite products is most critical for the improvement of the rainfall retrieval algorithm and its further applications. More available data from both rain gauges and the satellite products will be incorporated into the assessment in the near future. Despite this limitation, we note that our results provide useful insights into the dependence of 
TABLE A1. Overview of rain gauge densities used in previous studies.

\begin{tabular}{|c|c|c|c|c|c|c|}
\hline ID & Regions & Area $\left(\times 100 \mathrm{~km}^{2}\right)$ & No. of gauges & $\begin{array}{l}\text { Density of gauge } \\
\text { network (gauges } \\
\text { per } 100 \mathrm{~km}^{2} \text { ) }\end{array}$ & Satellite rainfall product & References \\
\hline 1 & Bali & 57 & 3 & 0.053 & TRMM & As-Syakur et al. (2011) \\
\hline 2 & Bangladesh & 1476 & 31 & 0.021 & TRMM & Islam and Uyeda (2005) \\
\hline 3 & Bhutan & 36 & 5 & 0.14 & TRMM & Tang et al. (2016a) \\
\hline 4 & Burma & 1104 & 5 & 0.00453 & IMERG & Yuan et al. (2017) \\
\hline 5 & China & 24000 & 166 & 0.0069 & TRMM & Gao and Liu (2013) \\
\hline 6 & China & 96000 & 750 & 0.00781 & IMERG & Chen and $\mathrm{Li} \mathrm{(2016)}$ \\
\hline 7 & China & 96000 & 840 & 0.00875 & IMERG & Ning et al. (2016) \\
\hline 8 & China & 9465 & 165 & 0.01734 & IMERG & R. Wang et al. (2017) \\
\hline 9 & China & 96000 & 2400 & 0.025 & IMERG & Guo et al. (2016) \\
\hline 10 & China & 96000 & 2800 & 0.03 & IMERG & Tang et al. (2016b) \\
\hline 11 & China & 9763 & 537 & 0.055 & IMERG & Xu et al. (2017) \\
\hline 12 & China & 181 & 52 & 0.29 & TRMM & Yong et al. (2012) \\
\hline 13 & China & 100 & 34 & 0.34 & TRMM & Jiang et al. (2012) \\
\hline 14 & China & 9763 & 258 & 1.64 & IMERG & Ma et al. (2016) \\
\hline 15 & China & 1500 & 503 & 1 & TRMM & He et al. (2017) \\
\hline 16 & Ethiopia & 1100 & 12 & 0.011 & TRMM & Hirpa et al. (2010) \\
\hline 17 & Finland & 7000 & 400 & 0.057 & TRMM & Bolvin et al. (2009) \\
\hline 18 & India & 29800 & 400 & 0.013 & TRMM & Mitra et al. (2009) \\
\hline 19 & India & 29800 & 2300 & 0.077 & TRMM & Prakash et al. (2015) \\
\hline 20 & India & 29800 & 7000 & 0.235 & IMERG & Prakash et al. (2018) \\
\hline 21 & Iran & 1500 & 13 & 0.00867 & IMERG & Siuki et al. (2017) \\
\hline 22 & Iran & 16482 & 1180 & 0.072 & TRMM & Moazami et al. (2013) \\
\hline 23 & Iran & 40 & 43 & 1 & IMERG & Sharifi et al. (2016) \\
\hline 24 & Kenya & 127 & 12 & 0.094 & TRMM & Ouma et al. (2012) \\
\hline 25 & Kyrgyzstan & 1985 & 35 & 0.0176 & TRMM & Karaseva et al. (2012) \\
\hline 26 & La Plata basin & 32000 & 3400 & 0.106 & TRMM & Su et al. (2008) \\
\hline 27 & Mekong River & 7950 & 53 & 0.0067 & IMERG & W. Wang et al. (2017) \\
\hline 28 & Oklahoma & 1500 & 944 & 0.629 & TRMM & Gourley et al. (2010) \\
\hline 29 & Saudi Arabia & 30000 & 29 & 0.001 & TRMM & Almazroui (2011) \\
\hline 30 & South America & 180000 & 1500 & 0.0083 & TRMM & Rozante et al. (2010) \\
\hline 31 & South Korea & 1200 & 520 & 0.43 & TRMM & Sohn et al. (2010) \\
\hline 32 & United States & 30 & 33 & 1.1 & TRMM & Prat and Barros (2010) \\
\hline 33 & Zambia & 1570 & 29 & 0.018 & TRMM & Hughes (2006) \\
\hline 34 & Zambia & 290 & 18 & 0.062 & TRMM & Hughes (2006) \\
\hline 35 & Zambia & 17 & 2 & 0.117 & TRMM & Hughes (2006) \\
\hline
\end{tabular}

the satellite rainfall products on both gauge density and rainfall intensity and provide a valuable reference for updating the rainfall retrieval algorithm for the IMERG rainfall product.

Acknowledgments. This study was supported by the Ministry of Science and Technology (2016YFC0402701, 2016YFA0601603), the National Science Foundation of China (91647205), and the foundation of State Key Laboratory of Hydroscience and Engineering of Tsinghua University (2016-KY-03). The authors would like to acknowledge the Hydrology Bureau in the Ministry of Water Resources of China for maintaining the rain gauge observations. Arrangements to obtain the datasets can be made by contacting the corresponding author (tianfq@tsinghua.edu.cn).

\section{APPENDIX A \\ Overview of Rain Gauge Densities}

Table A1 contains an overview of rain gauge densities used in previous studies.

\section{APPENDIX B}

\section{POD Dependency on Gauge Density under Light Rainfall}

Figure B1 shows a schematic of the dependency of POD on gauge density under light rainfall intensity. 

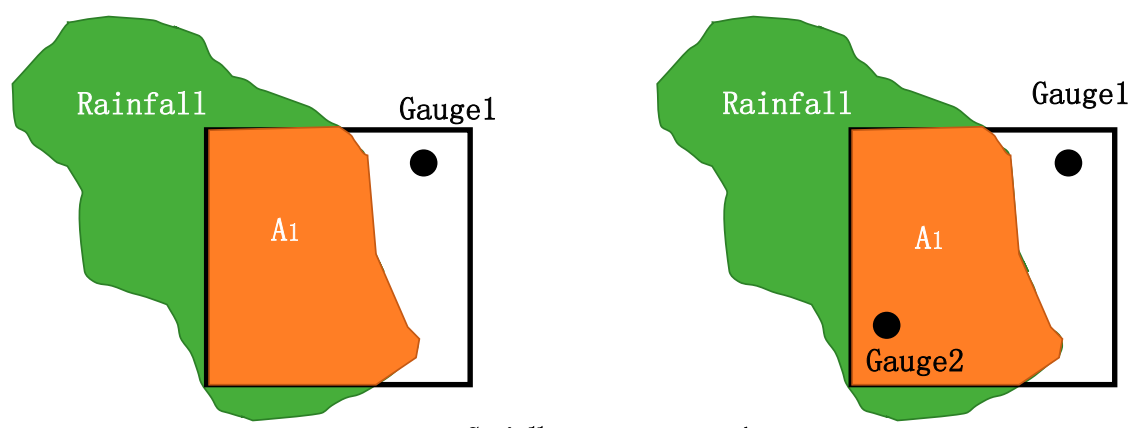

$$
\begin{aligned}
& \text { Gridbox area }=\mathrm{A} \\
& \text { Rainfall area in gridbox }=A 1
\end{aligned}
$$

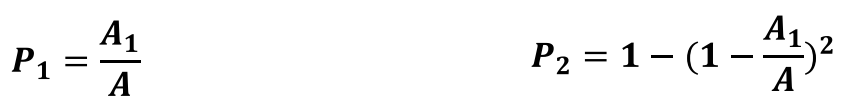

FIG. B1. Schematic of the dependency of POD on gauge density under light rainfall intensity. The green area represents the spatial coverage of rainfall, the black square represents a GPM grid box (approximately $100 \mathrm{~km}^{2}$ ), and the black dot represents a rain gauge. Note that $P_{1}$ is the probability that one gauge detects a rainfall event, and $P_{2}$ is the probability that at least one of the two gauges detects a rainfall event. The probability $P_{2}$ is no smaller than $P_{1}$ because the ratio of $A_{1}$ to $A$ is no larger than 1.

\section{REFERENCES}

Almazroui, M., 2011: Calibration of TRMM rainfall climatology over Saudi Arabia during 1998-2009. Atmos. Res., 99, 400-414, https://doi.org/10.1016/j.atmosres.2010.11.006.

Amitai, E., W. Petersen, X. Llort, and S. Vasiloff, 2012: Multiplatform comparisons of rain intensity for extreme precipitation events. IEEE Trans. Geosci. Remote Sens., 50, 675-686, https://doi.org/10.1109/TGRS.2011.2162737.

As-Syakur, A. R., T. Tanaka, R. Prasetia, I. K. Swardika, and I. W. Kasa, 2011: Comparison of TRMM Multisatellite Precipitation Analysis (TMPA) products and daily-monthly gauge data over Bali. Int. J. Remote Sens., 32, 8969-8982, https://doi.org/10.1080/01431161.2010.531784.

Bolvin, D. T., R. F. Adler, G. J. Huffman, E. J. Nelkin, and J. P. Poutiainen, 2009: Comparison of GPCP monthly and daily precipitation estimates with high-latitude gauge observations. J. Appl. Meteor. Climatol., 48, 1843-1857, https://doi.org/ 10.1175/2009JAMC2147.1.

Chen, F., and X. Li, 2016: Evaluation of IMERG and TRMM 3B43 monthly precipitation products over mainland China. Remote Sens., 8, 472, https://doi.org/10.3390/rs8060472

Ding, Y., and J. Zhang, 2009: Rainstorm and Flood. Meteorological Press, $290 \mathrm{pp}$.

Gao, Y. C., and M. F. Liu, 2013: Evaluation of high-resolution satellite precipitation products using rain gauge observations over the Tibetan Plateau. Hydrol. Earth Syst. Sci., 17, 837-849, https://doi.org/10.5194/hess-17-837-2013.

Girons Lopez, M., H. Wennerström, L. Å. Nordén, and J. Seibert, 2015: Location and density of rain gauges for the estimation of spatial varying precipitation. Geogr. Ann., 97, 167-179, https:// doi.org/10.1111/geoa.12094.

Goodrich, D. C., J.-M. Faurès, D. A. Woolhiser, L. J. Lane, and S. Sorooshian, 1995: Measurement and analysis of small-scale convective storm rainfall variability. J. Hydrol., 173, 283-308, https://doi.org/10.1016/0022-1694(95)02703-R.

Gourley, J. J., Y. Hong, Z. L. Flamig, L. Li, and J. Wang, 2010: Intercomparison of rainfall estimates from radar, satellite, gauge, and combinations for a season of record rainfall. J. Appl. Meteor. Climatol., 49, 437-452, https://doi.org/ 10.1175/2009JAMC2302.1.

Guo, H., S. Chen, A. Bao, A. Behrangi, Y. Hong, F. Ndayisaba, J. Hu, and P. M. Stepanian, 2016: Early assessment of integrated multi-satellite retrievals for global precipitation measurement over China. Atmos. Res., 176-177, 121-133, https://doi.org/10.1016/j.atmosres.2016.02.020.

He, Z., L. Yang, F. Tian, G. Ni, A. Hou, and H. Lu, 2017: Intercomparisons of rainfall estimates from TRMM and GPM multisatellite products over the upper Mekong River basin. J. Hydrometeor., 18, 413-430, https://doi.org/ 10.1175/JHM-D-16-0198.1

Hirpa, F. A., M. Gebremichael, and T. Hopson, 2010: Evaluation of high-resolution satellite precipitation products over very complex terrain in Ethiopia. J. Appl. Meteor. Climatol., 49, 1044-1051, https://doi.org/10.1175/2009JAMC2298.1.

Hou, A. Y., and Coauthors, 2014: The Global Precipitation Measurement mission. Bull. Amer. Meteor. Soc., 95, 701-722, https://doi.org/10.1175/BAMS-D-13-00164.1.

Hu, Q., D. Yang, Z. Li, A. K. Mishra, Y. Wang, and H. Yang, 2014: Multi-scale evaluation of six high-resolution satellite monthly rainfall estimates over a humid region in China with dense rain gauges. Int. J. Remote Sens., 35, 1272-1294, https://doi.org/ 10.1080/01431161.2013.876118.

Huffman, G. J., and Coauthors, 2007: The TRMM Multisatellite Precipitation Analysis (TMPA): Quasi-global, multiyear, combined-sensor precipitation estimates at fine scales. J. Hydrometeor., 8, 38-55, https://doi.org/10.1175/JHM560.1. , D. T. Bolvin, D. Braithwaite, K. Hsu, R. Joyce, C. Kidd, E. J. Nelkin, and P. Xie, 2015a: NASA Global Precipitation Measurement (GPM) Integrated Multi-satellitE Retrievals for GPM (IMERG). IMERG ATBD, version 4.5, 30 pp., https://pmm.nasa. gov/sites/default/files/document_files/IMERG_ATBD_V4.5.pdf. , - , and E. J. Nelkin, 2015b: Integrated Multi-satellitE Retrievals for GPM (IMERG) technical documentation. NASA/GSFC Code 612 Tech. Doc., 48 pp., http://pmm.nasa. gov/sites/default/files/document_files/IMERG_doc.pdf. 
Hughes, D. A., 2006: Comparison of satellite rainfall data with observations from gauging station networks. J. Hydrol., 327, 399-410, https://doi.org/10.1016/j.jhydrol.2005.11.041.

Islam, N., and H. Uyeda, 2005: Comparison of TRMM 3B42 products with surface rainfall over Bangladesh. Proc. IEEE Int. Geoscience and Remote Sensing Symp., Seoul, South Korea, IEEE, 4112-4115, https://doi.org/10.1109/ IGARSS.2005.1525819.

Javanmard, S., A. Yatagai, M. I. Nodzu, J. Bodaghjamali, and H. Kawamoto, 2010: Comparing high-resolution gridded precipitation data with satellite rainfall estimates of TRMM 3B42 over Iran. Adv. Geosci., 25, 119-125, https://doi.org/ 10.5194/adgeo-25-119-2010.

Jiang, S., L. Ren, Y. Hong, B. Yong, X. Yang, F. Yuan, and M. Ma, 2012: Comprehensive evaluation of multi-satellite precipitation products with a dense rain gauge network and optimally merging their simulated hydrological flows using the Bayesian model averaging method. J. Hydrol., 452-453, 213-225, https://doi.org/10.1016/j.jhydrol.2012.05.055.

Karaseva, M. O., S. Prakash, and R. M. Gairola, 2012: Validation of high-resolution TRMM-3B43 precipitation product using rain gauge measurements over Kyrgyzstan. Theor. Appl. Climatol., 108, 147-157, https://doi.org/10.1007/s00704-011-0509-6.

Kim, K., J. Park, J. Baik, and M. Choi, 2017: Evaluation of topographical and seasonal feature using GPM IMERG and TRMM 3B42 over Far-East Asia. Atmos. Res., 187, 95-105, https://doi.org/10.1016/j.atmosres.2016.12.007.

Liu, Z., 2016: Comparison of Integrated Multisatellite Retrievals for GPM (IMERG) and TRMM Multisatellite Precipitation Analysis (TMPA) monthly precipitation products: Initial results. J. Hydrometeor., 17, 777-790, https://doi.org/10.1175/ JHM-D-15-0068.1.

Ma, Y., G. Tang, D. Long, B. Yong, L. Zhong, W. Wan, and Y. Hong, 2016: Similarity and error intercomparison of the GPM and its predecessor-TRMM Multisatellite Precipitation Analysis using the best available hourly gauge network over the Tibetan Plateau. Remote Sens., 8, 569, https://doi.org/ 10.3390/rs8070569.

Mitra, A. K., A. K. Bohra, M. N. Rajeevan, and T. N. Krishnamurti, 2009: Daily Indian precipitation analysis formed from a merge of rain-gauge data with the TRMM TMPA satellite-derived rainfall estimates. J. Meteor. Soc. Japan, 87A, 265-279, https:// doi.org/10.2151/jmsj.87A.265.

Moazami, S., S. Golian, M. R. Kavianpour, and Y. Hong, 2013: Comparison of PERSIANN and V7 TRMM Multi-satellite Precipitation Analysis (TMPA) products with rain gauge data over Iran. Int. J. Remote Sens., 34, 8156-8171, https://doi.org/ 10.1080/01431161.2013.833360.

Ning, S., J. Wang, J. Jin, and H. Ishidaira, 2016: Assessment of the latest GPM-Era high-resolution satellite precipitation products by comparison with observation gauge data over the Chinese mainland. Water, $\mathbf{8}, 481$, https://doi.org/10.3390/ w8110481.

Ouma, Y., T. Owiti, E. Kipkorir, J. Kibiiy, and R. Tateishi, 2012: Multitemporal comparative analysis of TRMM-3B42 satellite-estimated rainfall with surface gauge data at basin scales: Daily, decadal and monthly evaluations. Int. J. Remote Sens., 33, 7662-7684, https://doi.org/10.1080/ 01431161.2012.701347.

Prakash, S., A. K. Mitra, I. M. Momin, D. S. Pai, E. N. Rajagopal, and S. Basu, 2015: Comparison of TMPA-3B42 versions 6 and 7 precipitation products with gauge-based data over India for the southwest monsoon period. J. Hydrometeor., 16, 346-362, https://doi.org/10.1175/JHM-D-14-0024.1.

_- _ _- A. AghaKouchak, Z. Liu, H. Norouzi, and D. S. Pai, 2018: A preliminary assessment of GPM-based multi-satellite precipitation estimates over a monsoon dominated region. J. Hydrol., 556, 865-876, https://doi.org/10.1016/ j.jhydrol.2016.01.029.

Prat, O. P., and A. P. Barros, 2010: Assessing satellite-based precipitation estimates in the Southern Appalachian mountains using rain gauges and TRMM PR. Adv. Geosci., 25, 143-153, https://doi.org/10.5194/adgeo-25-143-2010.

Rozante, J. R., D. S. Moreira, L. G. G. De Goncalves, and D. A. Vila, 2010: Combining TRMM and surface observations of precipitation: Technique and validation over South America. Wea. Forecasting, 25, 885-894, https://doi.org/ 10.1175/2010WAF2222325.1.

Sahlu, D., E. I. Nikolopoulos, S. A. Moges, E. N. Anagnostou, and D. Hailu, 2016: First Evaluation of the day-1 IMERG over the upper Blue Nile basin. J. Hydrometeor., 17, 2875-2882, https:// doi.org/10.1175/JHM-D-15-0230.1.

Sharifi, E., R. Steinacker, and B. Saghafian, 2016: Assessment of GPM-IMERG and other precipitation products against gauge data under different topographic and climatic conditions in Iran: Preliminary results. Remote Sens., 8, 135, https://doi.org/ 10.3390/rs8020135.

Shen, Y., A. Xiong, Y. Wang, and P. Xie, 2010: Performance of high-resolution satellite precipitation products over China. J. Geophys. Res., 115, 355-365, https://doi.org/10.1029/ 2009JD012097.

Siuki, S. K., B. Saghafian, and S. Moazami, 2017: Comprehensive evaluation of 3-hourly TRMM and half-hourly GPM-IMERG satellite precipitation products. Int. J. Remote Sens., 38, 558-571, https://doi.org/10.1080/ 01431161.2016.1268735.

Sohn, B. J., H. J. Han, and E. K. Seo, 2010: Validation of satellitebased high-resolution rainfall products over the Korean peninsula using data from a dense rain gauge network. J. Appl. Meteor. Climatol., 49, 701-714, https://doi.org/ 10.1175/2009JAMC2266.1.

Su, F., Y. Hong, and D. P. Lettenmaier, 2008: Evaluation of TRMM Multisatellite Precipitation Analysis (TMPA) and its utility in hydrologic prediction in the La Plata Basin. J. Hydrometeor., 9, 622-640, https://doi.org/10.1175/ 2007JHM944.1.

Tan, J., W. A. Petersen, P. E. Kirstetter, and Y. Tian, 2017: Performance of IMERG as a function of spatiotemporal scale. J. Hydrometeor., 18, 307-319, https://doi.org/10.1175/ JHM-D-16-0174.1.

Tang, G., Z. Zeng, D. Long, X. Guo, B. Yong, W. Zhang, and Y. Hong, 2016a: Statistical and hydrological comparisons between TRMM and GPM level-3 products over a midlatitude basin: Is day-1 IMERG a good successor for TMPA 3B42V7? J. Hydrometeor., 17, 121-137, https://doi.org/ 10.1175/JHM-D-15-0059.1.

_ Y. Y. Ma, D. Long, L. Zhong, and Y. Hong, 2016b: Evaluation of GPM day-1 IMERG and TMPA version-7 legacy products over Mainland China at multiple spatiotemporal scales. J. Hydrol., 533, 152-167, https://doi.org/10.1016/j.jhydrol.2015.12.008.

Turk, F. J., and P. Xian, 2013: An assessment of satellite-based high resolution precipitation datasets for atmospheric composition studies in the maritime continent. Atmos. Res., 122, 579-598, https://doi.org/10.1016/j.atmosres.2012.02.017. 
United Nations, 2006: Global survey of early warning systems. Tech. Rep., 46 pp., http://www.unisdr.org/2006/ppew/info-resources/ ewc3/Global-Survey-of-Early-Warning-Systems.pdf.

Wang, R., J. Chen, and X. Wang, 2017: Comparison of IMERG level-3 and TMPA 3B42V7 in estimating typhoon-related heavy rain. Water, 9, 276, https://doi.org/10.3390/w9040276.

Wang, W., H. Lu, T. Zhao, L. Jiang, and J. Shi, 2017: Evaluation and comparison of daily rainfall from latest GPM and TRMM products over the Mekong River basin. IEEE J. Sel. Top. Appl. Earth Obs. Remote Sens., 10, 2540-2549, https://doi.org/ 10.1109/JSTARS.2017.2672786.

WMO, 1965: Guide to hydrometeorological practices. WMO-168, $82 \mathrm{pp}$.

Xu, R., F. Tian, L. Yang, H. Hu, H. Lu, and A. Hou, 2017: Ground validation of GPM IMERG and TRMM 3B42V7 rainfall products over southern Tibetan Plateau based on a highdensity rain gauge network. J. Geophys. Res. Atmos., 122, 910-924, https://doi.org/10.1002/2016JD025418.

Yong, B., Y. Hong, L. L. Ren, J. J. Gourley, G. J. Huffman, X. Chen, W. Wang, and S. I. Khan, 2012: Assessment of evolving TRMM-based multisatellite real-time precipitation estimation methods and their impacts on hydrologic prediction in a high latitude basin. J. Geophys. Res., 117, D09108, https://doi.org/10.1029/2011JD017069.

Yuan, F., L. Zhang, K. Win, L. Ren, C. Zhao, Y. Zhu, S. Jiang, and Y. Liu, 2017: Assessment of GPM and TRMM Multi-Satellite Precipitation products in streamflow simulations in a data-sparse mountainous watershed in Myanmar. Remote Sens., 9, 302, https://doi.org/10.3390/ rs9030302. 